\title{
Contemporary Obstetrics and Gynaecology for Developing Countries
}

\author{
Okonofua F, Balogun JA, Odunsi K and Chilaka VN, Eds (2021). Second Edition. \\ Cham, Springer. ISBN 978-3-030-75384-9 (Hardcover), 978-3-030-75387-0 (Softcover), 978-3-030-75385-6 (eBook).
}

$\mathrm{T}$ his is the second edition of the book, and so it should still be viewed as a work in progress. It is important to have specialty reference textbooks from developing countries, with particular attention to the practices and limitations in these parts of the world, where large populations reside, with less than adequate healthcare funding and facilities. Some shortcomings highlighted here hopefully are focus points for future development. Most of the comments apply to several chapters, so the respective chapters are not listed, unless in instances where specific reference is necessary and specific chapters are involved.

The principle of the book is an excellent one, as it should serve as a repository of valuable information on the experiences and limitations of the practice of obstetrics and gynecology in developing countries. Such a reference text for conditions and care in developing countries is also of value to specialists practicing in developed settings. Apart from when such specialists go to work in developing countries, migration and international travel now mean that women from developing countries are often in developed countries and may present to specialists in developed countries, who may not be fully familiar with the variants of the conditions presenting to them.

The structure of chapters is excellent, with each chapter starting with a section on 'Learning Objectives', which sets out what the chapter is about and where relevant, emphasis on levels of preventative measures or initiatives, which are of vital value in settings with limited resources.

Contributors to the book have come mainly from sub-Saharan Africa, with international contribution from the UK, USA, Canada, Australia, and the Middle East. The sub-Saharan contingent of contributors is, however, from institutions in Nigeria and South Africa. This geographic limitation would not have been an issue had it not reflected frequently in the clinical practice experience cited by the author from these institutions. Considering that the title of the book implies that it is aimed at 'developing countries', drawing contributors and reflecting clinical experience from a very small number of developing countries can only be regarded as limited representation of experience and practice in developing countries.

The range of topics is very wide, including chapters on conventional obstetrics and gynecology and chapters

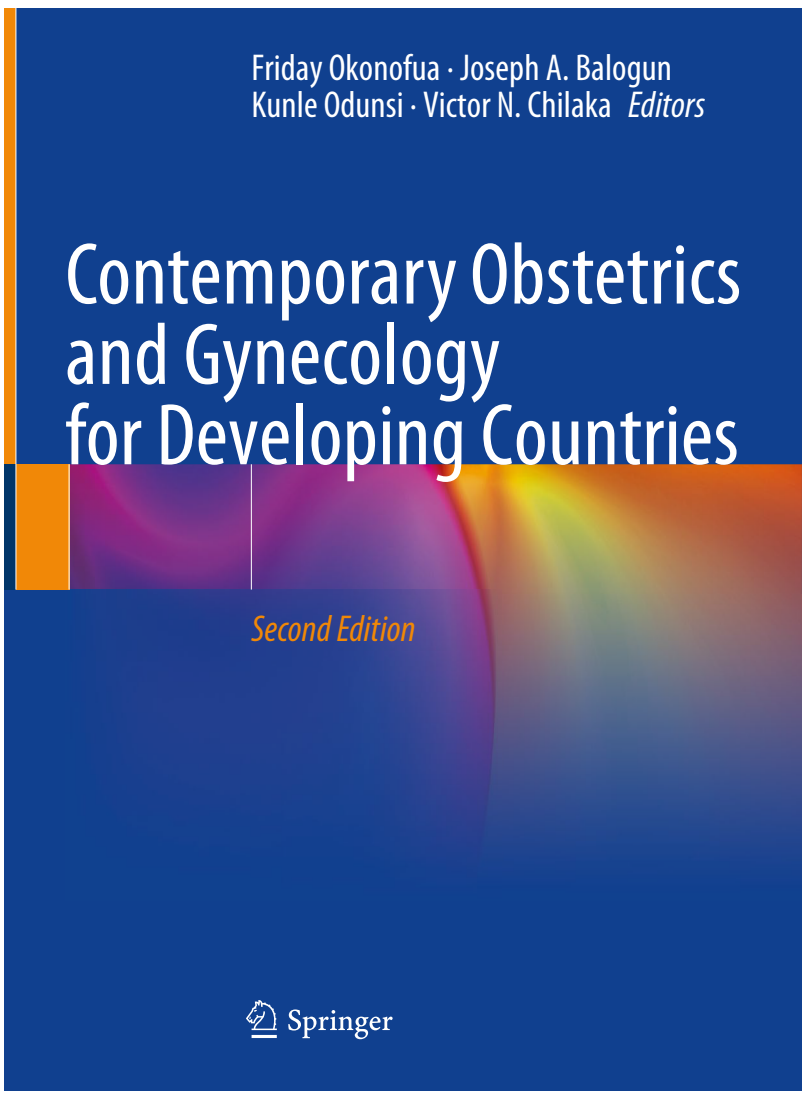

related to molecular biology of cancer, palliative care, leadership, health management, human rights, and professional associations. While all of these may be valuable to all trainees and clinicians, they may be needed at different times and depths. Putting these wide-ranging topics together in one book makes the book's focus rather unclear. The question will be whether one large volume is better than smaller but more focused volumes. In other words, the book may be attempting to serve more than one group of users. Only the users can fully answer that question.

The depth to which the chapters go is also variable. Some chapters are very basic, while some go to the level of detail that would be considered adequate for a reference textbook. This may be a reflection of the sheer scope that the book has adopted, and the range of topics covered, that is, its wide scope has resulted in low detail in 
parts. This makes it difficult to determine if the book is most suited for undergraduate, postgraduate, or both. If the book is intended for graduate users, the chapters with basic content may not justify their place.

In recognizing that many procedures or items of equipment that are in everyday use in developed countries may not be available in many parts of the developing world, illustrations and high-resolution images are of great educational valuable for those without routine access to these procedures or equipment. The use of illustrations or images is very variable in this book, with some chapters well illustrated but the majority not.

Many chapters detail investigations and procedures limited to locally available ones. While this may serve the immediate objective of local education, a reference textbook for developing countries should have a wider scope than this. It is valuable for validated investigations and procedures in routine use all over the world to receive some attention in this textbook. Some of the book's users will be specialists, trainers, or other independent practitioners who should have comprehensive material, or trainees, who should have equally comprehensive knowledge base for their local practice. Many may also find themselves in developed countries and appear deficient if their training or reference textbook is lacking in comprehensive knowledge. More collaboration between contributors from developing and developed settings in the authorship of chapters could address this shortcoming. This focus on local information resources also applies to knowledge of and reference to internationally acclaimed reference works. For example, the chapter on maternal mortality cites Nigerian statistics and very little from other developing countries. For such topics, important works relating to audit or interrogation of the statistics as done in the UK confidential enquiries or the World Health Organisation's 'Beyond the numbers' publication are lessons of extreme value to all. Lessons from maternal and perinatal mortality audits and confidential enquiries are of great value in the drive to reduce rates. While it is not within the remit of this book to set these audits or enquiries up, it can play a big role in educating on them and promoting them.

Many chapters have not adequately addressed the role of medical imaging technologies, which, although may be limited or basic in developing countries, are of great value in improving clinical diagnosis, staging cancers and planning treatment of many obstetric and gynecological conditions. While the majority of public health settings in developing countries may not provide high-end investigations and facilities, many private health institutions now offer health care that is close to the standards available in developed countries and have clinicians with the training and practice experience to deliver these. A textbook of contemporary practice, aimed for developing countries should have significant detail on such technologies.
The variable depth of chapters also reflects in the variable emphasis on counselling and multi-disciplinary work, which are important aspects of contemporary practice. Counselling is important for informed consent and should be a universal aim for clinicians. It is currently not a high priority area in developing countries and should be part of the teaching of the specialty. Multidisciplinary input is increasingly important for the care of women in all parts of the world, and any contemporary textbook should promote this mode of working. It is just as important, probably even more so where resources and skills may be limited, that clinicians collaborate and pool their expertise to improve the care delivered through a team approach, compared to the expertise of individuals.

Some chapters are brief and if properly addressed would have significant overlap or duplication with some others. In this book, some of such overlap results in the subject not being adequately addressed in the chapters in which it features. For example, a chapter on 'inherited' bleeding disorders contains conditions that are not inherited and overlaps with the chapter on hematological disorders, which, in itself, could be a better collective for subjects spread thinly in other chapters. This is an area where collaboration between contributors would probably have been useful and produced a shorter chapter list but more depth to the chapters and subjects involved.

Some contributors have included statements that may be best described as opinions, without providing an evidence base, but presented these as facts. While the experienced specialist will recognize these as opinions, trainees using the book may take these and reproduce them as facts from an authoritative source.

There is a section on 'Health Systems Organisation, Research Methodology and Biostatistics'. This section no doubt contains valuable chapters written by eminent and international contributors but along with a handful of chapters in other sections, it may very well be better placed in separate book, so the rest of the book can stay in focus.

In conclusion, this is a valuable textbook of obstetrics and gynecology practice in developing countries but with shortcomings on scope, focus, and the geographic spread of the practice it reflects.

\section{Conflict of interest and funding}

This reviewer has no conflict of interest and funding to declare.

\section{Olujimi A. Jibodu, FRCOG}

Honorary Consultant Obstetrician \& Gynaecologist/

Honorary Lecturer

York Teaching Hospital/Hull York Medical School,York, United Kindgom 